\section{Diagnostikk av alvorlige medfødte hjertefeil i Norge 2016}

ORIGINALARTIKKEL

\section{JARLE JORTVEIT}

E-post: jarle.jortveit@sshf.no

Hjerteseksjonen

Medisinsk avdeling

Sørlandet sykehus

Arendal

Han har bidratt med idé, utforming, tolking av data, litteratursøk, revisjon og godkjenning av manus. Jarle Jortveit er ph.d., spesialist i indremedisin og i hjertesykdommer og seksjonsoverlege/forsker. Forfatter har fylt ut ICMJE-skjemaet og oppgir ingen interessekonflikter.

\section{GUNNAR WIK}

Barne- og ungdomsklinikken

Oslo universitetssykehus, Rikshospitalet

og

Barne- og ungdomsavdelingen

Sørlandet sykehus

Kristiansand

Han har bidratt med idé, utforming, innsamling og tolking av data, revisjon og godkjenning av manus.

Gunnar Wik er spesialist i barnesykdommer, overlege (Sørlandet sykehus) og ph.d.-kandidat (Oslo universitetssykehus).

Forfatter har fylt ut ICMJE-skjemaet og oppgir ingen interessekonflikter.

\section{JOSTEIN STRAND ØDEGAARD}

Universitetet i Oslo

Han har bidratt med datainnsamling, revisjon og godkjenning av manus.

Jostein Strand Ødegaard er medisinstudent.

Forfatter har fylt ut ICMJE-skjemaet og oppgir ingen interessekonflikter.

\section{VASILIS SITRAS}

Fostermedisinsk avdeling

Kvinneklinikken

Oslo universitetssykehus

Vasilis Sitras har bidratt med idé, revisjon og godkjenning av manus.

Vasilis Sitras er ph.d., spesialist i fødselshjelp og kvinnesykdommer og overlege.

Forfatter har fylt ut ICMJE-skjemaet og oppgir ingen interessekonflikter.

\section{KARL VIKTOR PERMINOW}

Barne- og ungdomsklinikken

Oslo universitetssykehus, Rikshospitalet

Han har bidratt med idé, revisjon og godkjenning av manus.

Karl Viktor Perminow er spesialist i barnesykdommer, overlege og ansvarlig for prenatal diagnostikk 
ved Barnekardiologisk avdeling.

Forfatter har fylt ut ICMJE-skjemaet og oppgir ingen interessekonflikter.

\section{HENRIK HOLMSTRØM}

Barnekardiologisk avdeling

Barne- og ungdomsklinikken

Oslo universitetssykehus

og

Institutt for klinisk medisin

Universitetet i Oslo

Han har bidratt med idé, utforming, innsamling og tolking av data, litteratursøk, revisjon og godkjenning av manus.

Henrik Holmstrøm er dr.med., spesialist i barnesykdommer, overlege og professor.

Forfatter har fylt ut ICMJE-skjemaet og oppgir ingen interessekonflikter.

\section{BAKGRUNN}

De fleste strukturelle medfødte hjertefeil kan identifiseres før fødsel ved ultralydundersøkelse i svangerskapet og ved rutineundersøkelser under barseloppholdet, men hos noen erkjennes ikke hjertefeilen før utskrivning. Deteksjonsraten ved de ulike metodene er i liten grad undersøkt tidligere. I denne studien har vi undersøkt tidspunkt og metode for diagnose av alvorlige medfødte hjertefeil.

\section{MATERIALE OG METODE}

Alle barn med alvorlige hjertefeil født i Norge i 2016 og registrert ved Oslo universitetssykehus ble inkludert i denne studien. I tillegg ble informasjon om nemndbehandlede aborter hentet fra Medisinsk fødselsregister.

\section{RESULTATER}

Totalt 105 av 181 ( $58 \%$ ) alvorlige hjertefeil ble oppdaget før fødsel. I alt 51 (28 \%) svangerskap ble terminert. Blant de 73 levendefødte barna med ikke-prenatalt erkjent alvorlig hjertefeil ble 33 (45\%) oppdaget utenom rutinemessige undersøkelser og $9(\mathbf{1 2} \%)$ etter utskrivning fra sykehuset. Koarktasjon av aorta var vanligste diagnose ved sent oppdaget hjertefeil.

\section{FORTOLKNING}

Denne første nasjonale studien av diagnostikk av alvorlige medfødte hjertefeil i Norge viser at de fleste alvorlige medfødte hjertefeil oppdages før utskrivning fra barseloppholdet, men nesten halvparten diagnostiseres utenom rutineundersøkelser, og hos noen barn erkjennes ikke diagnosen før etter utskrivning. Resultatene indikerer også et behov for nye studier og et kvalitetsregister over medfødte hjertefeil for ytterligere å bedre diagnostikk og tidlig behandling.

Medfødte hjertefeil er definert som medfødte strukturelle forandringer i hjertet og/eller de store intratorakale karene med funksjonell eller potensielt funksjonell betydning (1). Hjertefeil er den vanligste medfødte misdannelsen og affiserer omtrent 1 av 100 levendefødte barn (2). De fleste medfødte hjertefeil har mindre klinisk betydning, men omtrent $1 / 4$ er alvorlige feil som krever tidlig identifisering og behandling $(2,3)$. Til tross for store fremskritt i diagnostikk og behandling, utgjør fremdeles medfødte hjertefeil en viktig årsak til sykdom og død i barnealder $(3,4)$.

Mange alvorlige medfødte hjertefeil kan oppdages før fødsel ved rutinemessig ultralydundersøkelse i svangerskapet (5). Ved norske sentre har prenatal deteksjonsrate for medfødte hjertefeil i tidligere rapporter variert fra $25 \%$ til 70 \% (5-7). Etter fødsel utføres klinisk undersøkelse av alle nyfødte barn for å avdekke blant annet medfødte hjertefeil. Likevel fant Meberg og medarbeidere at ca. $25 \%$ av hjertefeilene hos barn i Vestfold 1982-96 
ble oppdaget etter utskrivning fra sykehus (8). Tilsvarende funn er rapportert fra flere land $(9,10)$. Noen av disse barna har alvorlige hjertefeil og dør før de rekker frem til behandling (11). De siste tiårene har det vært en betydelig utvikling i den prenatale diagnostikken, og i 2013 ble også måling av oksygenmetningen innført i Norge som rutinemessig unders $ø$ kelse for å avdekke hjertefeil hos alle nyfødte barn før hjemreise etter barseloppholdet.

Pulsoksymetri har bedre prediktiv verdi for påvisning av hjertefeil enn klinisk undersøkelse alene og er rapportert å redusere antall oversette tilfeller med ca. $10 \%(12,13)$. For enkelte alvorlige hjertefeil slik som f.eks. koarktasjon av aorta har imidlertid pulsoksymetri lav sensitivitet (14). Alvorlige hjertefeil blir derfor fortsatt oversett, og screening av alle nyfødte med ekkokardiografi er foreslått (15).

Hensikten med denne studien var å undersøke diagnosetidspunkt og diagnosemetode ved alvorlige medfødte hjertefeil i Norge i 2016.

\section{Materiale og metode}

Opplysninger om nemndbehandlede aborter på grunn av hjertefeil i Norge i 2016 ble hentet fra Medisinsk fødselsregisters statistikkbank (16). Data vedrørende levendefødte barn med alvorlige medfødte hjertefeil i 2016 ble hentet fra Oslo universitetssykehus' register over medfødte hjertefeil. For å få med sent oppdagede hjertefeil ble datauttrekket utført 31.12.2017. Oslo universitetssykehus har landsfunksjon for behandling av barn med alvorlige medfødte hjertefeil, og alle pasienter behandlet ved Barnekardiologisk avdeling føres i registeret. I tillegg til registeropplysningene ble supplerende informasjon innhentet ved gjennomgang av medisinske journaler.

Alle medfødte hjertefeil ble klassifisert i henhold til International Paediatric and Congenital Cardiac Code (17). Vi delte videre alle medfødte hjertefeil i alvorlige og ikkealvorlige hjertefeil (3). Følgende medfødte hjertefeil ble klassifisert som alvorlige: Atrioventrikulær septumdefekt, truncus arteriosus, totalt anomalt innmunnende lungevener, Fallots tetrade, pulmonal atresi, hypoplastisk venstre hjerte-syndrom, kongenitt korrigert transposisjon av de store arterier, transposisjon av de store arteriene, dobbelt utløpende høyre ventrikkel, koarktasjon av aorta, andre isolerte klaffefeil og andre alvorlige hjertefeil. Ikke-alvorlige medfødte hjertefeil ble ikke inkludert. Alvorlige tilleggsdiagnoser med stor betydning for barnets helse og/eller utvikling, som andre medfødte misdannelser og syndromer, ble også registrert. Alle journaler ble gjennomgått av to erfarne barnekardiologer, og tvilstilfeller ble klassifisert etter konsensus i forfattergruppen.

Kontinuerlige variabler er presentert som median (interkvartilbredde) og kategoriske variabler med antall og andel i prosent.

Studien er vurdert som et kvalitetssikringsprosjekt uten krav om godkjenning fra regional etisk komité. Datainnsamling og håndtering av persondata er godkjent av personvernombudet for forskning ved Oslo universitetssykehus.

\section{Resultater}

I perioden 1.1.2016-31.12.2016 ble det registrert 59852 levendefødte barn, 404 dødfødte og 272 nemndbehandlede aborter i Norge (16). Ved de nemndbehandlede abortene var det registrert hjertefeil i 51 tilfeller. I samme periode ble det registrert 130 barn med en alvorlig medfødt hjertefeil i Oslo universitetssykehus' register over medfødte hjertefeil. Forekomsten av alvorlige medfødte hjertefeil i Norge i 2016 var følgelig 299 per 100 ooo graviditeter og 217 per 100 ooo levendefødte barn.

I tillegg til de 51 abortene av barn med hjertefeil ble diagnosen medfødt hjertefeil stilt hos 54 av 130 levendefødte barn før fødsel. Estimert total prenatal deteksjonsrate var følgelig $58 \%$.

Fordelingen av de ulike alvorlige medfødte hjertefeilene hos levendefødte barn er vist i 
tabell 1. Andre medfødte misdannelser og syndromer forekom hyppig (39 av 130 (30\%)

barn), men i varierende grad ved ulike hjertefeil.

\section{Tabell 1}

Fordeling av diagnoser for alvorlige medfødte hjertefeil og samtidig forekomst av andre alvorlige tilleggsdiagnoser (f.eks. medfødte misdannelser og syndromer) i Norge i 2016. Antall (n).

\begin{tabular}{|lcc|}
\hline Diagnose & Antall barn Andre alvorlige tilleggsdiagnoser \\
\hline Koarktasjon av aorta & 26 & 2 \\
\hline Andre alvorlige hjertefeil & 26 & 7 \\
\hline Atrioventrikulær septumdefekt & 21 & 15 \\
\hline Transposisjon av de store arteriene & 14 & 0 \\
\hline Andre isolerte klaffefeil & 13 & 6 \\
\hline Fallots tetrade & 12 & 3 \\
\hline Dobbelt utløpende høyre ventrikkel & 7 & 3 \\
\hline Pulmonalatresi & 6 & 3 \\
\hline Hypoplastisk venstre hjerte-syndrom & 5 & 0 \\
\hline Totalt & 130 & 39 \\
\hline
\end{tabular}

Diagnosetidspunkt ved de ulike hjertefeilene hos de levendefødte barna er presentert i tabell 2. Hos 73 av 130 (56\%) barn ble diagnosen stilt etter fødsel, og blant disse ble diagnosen stilt etter utskrivning fra sykehus hos ni (12\%) barn. Årsakene til at hjertefeilen ble oppdaget etter fødsel er presentert i figur 1. Hos 35 av de 73 (48 \%) barna ble hjertefeilen oppdaget ved rutineundersøkelser. Av disse ble 16 (46\%) barn identifisert ved legeundersøkelse før utskrivning fra barselavdeling. Vanligste kliniske funn som indikerte hjertefeil ved denne legeundersøkelsen var bilyd (15 av 16 (94\%) barn) ved auskultasjon over hjertet. Hos 11 av 35 barn hvor hjertefeilen ble oppdaget ved rutineundersøkelse etter fødsel, skjedde dette som følge av pulsoksymetriundersøkelse. Færre enn fem barn født i 2016 fikk hjertefeildiagnose i forbindelse med oppfølging på helsestasjonen. Hovedårsaken hos alle som ble henvist derfra, var bilyd over hjertet.

\section{Tabell 2}

Tidspunkt for diagnose hos levendefødte barn med alvorlige medfødte hjertefeil i Norge i 2016. Antall (n).

\begin{tabular}{|lccccc|}
\hline Diagnose & $\begin{array}{c}\text { Antall } \\
\text { barn }\end{array}$ & $\begin{array}{c}\text { Prenatal } \\
\text { diagnose }\end{array}$ & $\begin{array}{c}\text { Før } \\
\text { utskrivning } \\
\text { fra sykehus }\end{array}$ & $\begin{array}{c}\text { Etter } \\
\text { utskrivning } \\
\text { fra sykehus }\end{array}$ & $\begin{array}{c}\text { Ukjent diagnose- } \\
\text { tidspunkt }\end{array}$ \\
\hline $\begin{array}{l}\text { Koarktasjon av } \\
\text { aorta }\end{array}$ & 26 & 5 & 14 & 7 & 0 \\
\hline $\begin{array}{l}\text { Andre alvorlige } \\
\text { hjertefeil }\end{array}$ & 26 & 11 & 12 & 2 & 1 \\
\hline $\begin{array}{l}\text { Atrioventrikulær } \\
\text { septumdefekt }\end{array}$ & 21 & 10 & 10 & 0 & 1 \\
\hline $\begin{array}{l}\text { Transposisjon av de } \\
\text { store arteriene }\end{array}$ & 14 & 7 & 7 & 0 & 0 \\
\hline $\begin{array}{l}\text { Andre isolerte } \\
\text { klaffefeil }\end{array}$ & 13 & 2 & 11 & 0 & 0 \\
\hline Fallots tetrade & 12 & 8 & 4 & 0 & 1 \\
\hline $\begin{array}{l}\text { Dobbelt utløpende } \\
\text { høyre ventrikkel }\end{array}$ & 7 & 3 & 3 & 0 & 0 \\
\hline Pulmonalatresi & 6 & 4 & 2 & 0 & 0 \\
\hline
\end{tabular}




\begin{tabular}{|lccccc|}
\hline Diagnose & $\begin{array}{c}\text { Antall Prenatal } \\
\text { barn }\end{array}$ & $\begin{array}{c}\text { Før } \\
\text { diagnose }\end{array}$ & $\begin{array}{c}\text { Etter } \\
\text { utskrivning } \\
\text { fra sykehus }\end{array}$ & $\begin{array}{c}\text { Ukjent diagnose- } \\
\text { fra sykehus }\end{array}$ & tidspunkt \\
\hline $\begin{array}{l}\text { Hypoplastisk } \\
\text { venstre hjerte- } \\
\text { syndrom }\end{array}$ & 5 & 4 & 1 & 0 & 0 \\
\hline Totalt & 130 & 54 & 64 & 9 & 3 \\
\hline
\end{tabular}

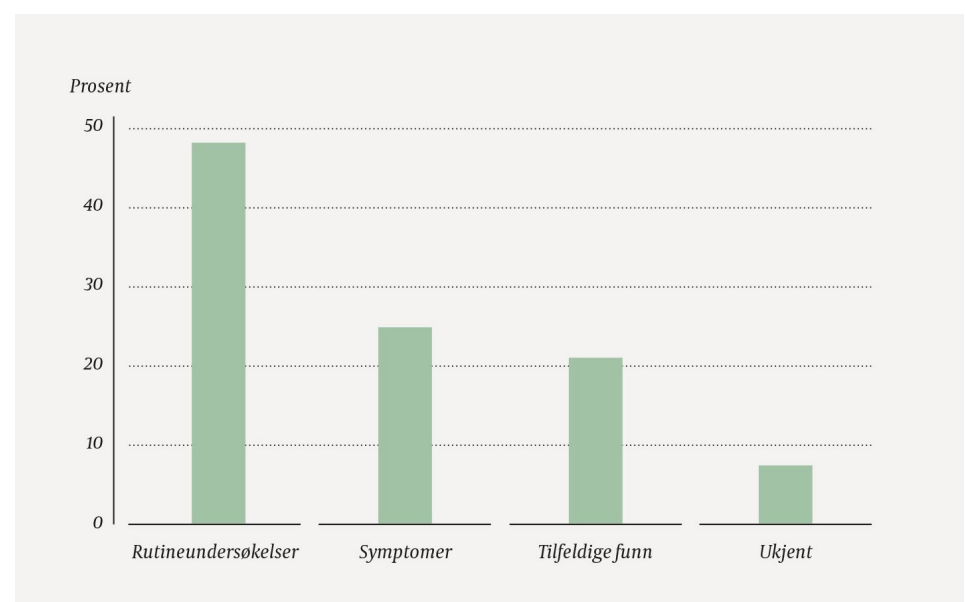

Figur 1 Årsaker til identifisering av alvorlig medfødt hjertefeil etter fødsel i Norge i 2016.

Median tid til diagnose for alvorlig medfødt hjertefeil etter fødsel var 2 (1-6) dager. Median tid til diagnose hos de ni barna hvor diagnosen først ble erkjent etter utskrivning fra sykehus var 114 dager (18-318 dager). Koarktasjon av aorta var vanligst ved sen diagnose ( 7 av $9(78 \%)$ barn). Hos fire av syv barn med sent oppdaget koarktasjon ble hjertefeilen oppdaget etter auskultasjon av bilyd over hjertet, mens tilstanden debuterte med symptomer hos de $\emptyset$ vrige.

\section{Diskusjon}

Denne studien av påvisning av alvorlige medfødte hjertefeil i Norge i 2016 viste at $58 \%$ av hjertefeilene ble oppdaget før fødsel. Hos $48 \%$ av barna med postnatal diagnose ble hjertefeilen oppdaget på grunn av rutineundersøkelser. Hos $12 \%$ av de levendefødte barna uten kjent hjertefeil ble tilstanden oppdaget først etter utskrivning fra sykehuset. Koarktasjon av aorta var vanligste diagnose ved sent oppdaget hjertefeil.

Rutinemessig ultralydundersøkelse i svangerskapet identifiserer mange fostre med hjertefeil. Dette gjør at fødselen av barn med alvorlige hjertefeil kan skje ved et senter med barnekardiologisk og barnehjertekirurgisk kompetanse, men har også ført til terminering av flere svangerskap der hjertefeil er påvist (3). Nye internasjonale retningslinjer for ultralydunders $ø$ kelsen i 2013 inkluderte flere bildeprojeksjoner som standard (18). Dette har blant annet i en amerikansk studie vist å øke deteksjonsraten fra $44 \%$ til 69\% (19). Denne nasjonale studien bekrefter at den prenatale deteksjonsraten er sammenlignbar med tidligere funn fra regionale norske sentre og blant annet fra Danmark (5, 6, 20), men studien er for liten til å kunne undersøke effekten av nye retningslinjer.

Siden alvorlige hjertefeil ikke alltid lar seg diagnostisere prenatalt, vil fortsatt noen barn fødes med alvorlige hjertefeil. For disse er rask diagnostikk og korrekt behandling avgjørende for utfallet. Mange av hjertefeilene som ble oppdaget etter fødsel, ble identifisert ved legeunders $\emptyset$ kelse før utskrivning fra barseloppholdet. Dette bekrefter betydningen av rutinemessig barnelegeundersøkelse av alle nyfødte og er også et argument mot tidlig utskrivning fra barselavdelinger. Vi vil også påpeke viktigheten av rask avklaring med ekkokardiografi dersom den kliniske unders $\emptyset$ kelsen gir mistanke om hjertefeil.

Bilyd ved auskultasjon over hjertet var det vanligste kliniske funnet som indikerte hjertefeil. Det er imidlertid viktig å være klar over at bilyd ofte er til stede også hos barn uten hjertefeil, og at omtrent halvparten av alle barn med hjertefeil ikke har bilyd (21). 
Screening med pulsoksymetri er en enkel og billig undersøkelse som ble innført i Norge i 2013 (22). Flere studier har vist at dette er et kostnadseffektivt tiltak (23). I denne studien ble $15 \%$ av hjertefeilene med postnatal diagnose identifisert som følge av pulsoksymetri. Noen av hjertefeilene som ble oppdaget ved pulsoksymetri, ville sannsynligvis også ha blitt oppdaget ved rutinemessig legeundersøkelse. Vi vet derfor ikke eksakt i hvilken grad metoden har redusert antall barn med ikke-erkjente diagnoser.

Pulsoksymetri har lav sensitivitet for venstresidige obstruksjoner og spesielt ved koarktasjon av aorta, der oksygenmetningen vanligvis er normal eller nær normal (14). Koarktasjon var i denne studien den vanligste ikke-erkjente hjertefeilen ved utskrivning fra barseloppholdet. Hos barn med en trang koarktasjon er systemisk sirkulasjon avhengig av en persisterende ductus arteriosus, og symptomer vil først komme når ductus lukkes. Dette skjer vanligvis i løpet av de første levedøgnene, men kan også inntreffe etter flere uker. Ved en kritisk stenose kan dette være en livstruende tilstand med rask utvikling av alvorlig metabolsk acidose, kardiogent sjokk og hjertestans. Umiddelbar diagnose og behandling for å opprettholde blodstrøm gjennom ductus arteriosus er livreddende. Tilsvarende symptomutvikling kan skje ved andre ductusavhengige hjertefeil som blant annet kritisk aortastenose, hypoplastisk venstre hjerte-syndrom, transposisjon av de store arterier og trikuspidal- eller pulmonalatresi.

I enkelte studier er rutinemessig ekkokardiografisk undersøkelse av alle nyfødte vist å redusere antallet ikke-erkjente alvorlige hjertefeil, men unders $ø$ kelsen er svært kompetanse- og ressurskrevende og har omtrent $5 \%$ falskt positive funn $(24,25)$. Norsk tradisjon forbeholder ekkokardiografisk unders $ø$ kelse til barn med prenatal diagnose, funn ved rutineundersøkelser eller ved klinisk mistanke om hjertefeil. Vi har ikke undersøkt nytteverdien av ekkokardiografi i denne studien.

Vår studie omfatter en landsomfattende kohort av barn med alvorlige medfødte hjertefeil og inkluderer både nemndbehandlede aborter og levendefødte barn, men studien har også flere svakheter. Studien inkluderte kun pasienter født i 2016, og antall individer var relativt lavt. Ikke-alvorlige hjertefeil, som sannsynligvis i større grad oppdages senere i livet, ble ikke inkludert. Vi har ikke hatt mulighet til å kvalitetssikre antall nemndbehandlede aborter av barn med hjertefeil. Vi har heller ikke opplysninger om type hjertefeil og eventuell komorbiditet i denne gruppen. Norge har dessverre ikke et nasjonalt register over pasienter med medfødte hjertefeil. Selv om Oslo universitetssykehus har landsfunksjon for behandling av alvorlige medfødte hjertefeil hos barn og unge, kan noen pasienter ha vært utredet og behandlet ved lokalsykehus uten at Oslo universitetssykehus har vært involvert. Disse vil følgelig ikke være inkludert i denne studien.

Oppsummert viser denne studien at de fleste barn med alvorlige medfødte hjertefeil oppdages ved ultralydundersøkelse i svangerskapet eller ved rutineunders $ø$ kelser før utskrivning fra barseloppholdet. Blant barn som fikk påvist alvorlig hjertefeil etter fødselen, ble likevel nesten halvparten oppdaget utenom rutinemessige undersøkelser, på grunn av symptomer eller som tilfeldige funn. Hos noen barn, særlig ved koarktasjon av aorta, erkjennes imidlertid ikke diagnosen før etter utskrivning fra sykehus etter barseloppholdet. Vi vil understreke viktigheten av umiddelbar sykehusinnleggelse og rask vurdering av barnekardiolog av små barn med mistanke om alvorlig hjertefeil. Denne studien viser også at det er behov for løpende kvalitetssikring av metodene for å oppdage hjertefeil. Å etablere et nasjonalt kvalitetsregister over medfødte hjertefeil vil være et viktig verktøy i det arbeidet.

\section{HOVEDBUDSKAP}

Deteksjonsraten for alvorlige medfødte hjertefeil ved undersøkelse før fødsel var 58 \% i Norge i 2016

$45 \%$ av alle barn med en alvorlig medfødt hjertefeil diagnostisert etter fødsel ble oppdaget 
utenom etablerte rutineundersøkelser

$\mathbf{1 2}$ \% av barna med en alvorlig medfødt hjertefeil som ikke var erkjent før fødsel, ble utskrevet fra sykehus etter barselopphold uten riktig diagnose

\section{LITTERATUR:}

1. Mitchell SC, Korones SB, Berendes HW. Congenital heart disease in 56,109 births. Incidence and natural history. Circulation 1971; 43:323-32. [PubMed][CrossRef]

2. Leirgul E, Fomina T, Brodwall Ket al. Birth prevalence of congenital heart defects in Norway 1994-20o9-a nationwide study. Am Heart J 2014; 168: 956-64. [PubMed][CrossRef]

3. Jortveit J, Øyen N, Leirgul E et al. Trends in mortality of congenital heart defects. Congenit Heart Dis 2016; 11: 16o-8. [PubMed][CrossRef]

4. Erikssen G, Liestøl K, Seem E et al. Achievements in congenital heart defect surgery: a prospective, 40-year study of 7038 patients. Circulation 2015; 131:337-46, discussion 346. [PubMed][CrossRef]

5. Tegnander E, Williams W, Johansen OJ et al. Prenatal detection of heart defects in a non-selected population of 30,149 fetuses-detection rates and outcome. Ultrasound Obstet Gynecol 2006; 27: 252-65. [PubMed][CrossRef]

6. Eggebø TM, Heien C, Berget M et al. Routine use of color Doppler in fetal heart scanning in a lowrisk population. ISRN Obstet Gynecol 2012; 2012: 496935. [PubMed][CrossRef]

7. Acharya G, Sitras V, Maltau JM et al. Major congenital heart disease in Northern Norway: shortcomings of pre- and postnatal diagnosis. Acta Obstet Gynecol Scand 2004; 83: 1124-9. [PubMed][CrossRef]

8. Meberg A, Otterstad JE, Frøland G et al. Early clinical screening of neonates for congenital heart defects: the cases we miss. Cardiol Young 1999; 9: 169-74. [PubMed][CrossRef]

9. Wren C, Reinhardt Z, Khawaja K. Twenty-year trends in diagnosis of life-threatening neonatal cardiovascular malformations. Arch Dis Child Fetal Neonatal Ed 2008; 93: F33-5. [PubMed][CrossRef]

10. Peterson C, Ailes E, Riehle-Colarusso T et al. Late detection of critical congenital heart disease among US infants: estimation of the potential impact of proposed universal screening using pulse oximetry. JAMA Pediatr 2014; 168:361-70. [PubMed][CrossRef]

11. Abu-Harb M, Hey E, Wren C. Death in infancy from unrecognised congenital heart disease. Arch Dis Child 1994; 71: 3-7. [PubMed][CrossRef]

12. de-Wahl Granelli A, Wennergren M, Sandberg K et al. Impact of pulse oximetry screening on the detection of duct dependent congenital heart disease: a Swedish prospective screening study in 39,821 newborns. BMJ 2009; 338: a3037. [PubMed][CrossRef]

13. Meberg A, Andreassen A, Brunvand L et al. Pulse oximetry screening as a complementary strategy to detect critical congenital heart defects. Acta Paediatr 2009; 98: 682-6. [PubMed][CrossRef]

14. Valmari P. Should pulse oximetry be used to screen for congenital heart disease? Arch Dis Child Fetal Neonatal Ed 2007; 92: F219-24. [PubMed][CrossRef]

15. Postmyr KJ, Tegnander E, Meberg A. Kritiske hjertefeil hos nyfødte overses. Tidsskr Nor Legeforen 2014; 134: 194-6. [PubMed][CrossRef]

16. Medisinsk fødselsregister og Abortregisteret - statistikkbanker. M1: Medfødte misdannelser. http://statistikkbank.fhi.no/mfr/index.jsp?study-

http\%3A\%2F\%2F129.177.219.15\%3A80\%2Fobj\%2FfStudy\%2Fm1.medfodte.misdannelser\&cubehttp\%3A\%2F\%2F129.177.219.15\%3A80\%2Fobj\%2FfCube\%2Fm1.medfodte.misdannelser_C1\&modecube\&v=2\&topyes\&languageno (15.6.2018).

17. International Society for Nomenclature of Paediatric and Congenital Heart Disease. International Paediatric and Congenital Cardiac Code. http://ipccc.net (3.11.2018).

18. Carvalho JS, Allan LD, Chaoui R et al. ISUOG Practice Guidelines (updated): sonographic screening examination of the fetal heart. Ultrasound Obstet Gynecol 2013; 41:348-59. [PubMed][CrossRef]

19. Hill GD, Block JR, Tanem JB et al. Disparities in the prenatal detection of critical congenital heart 
disease. Prenat Diagn 2015; 35: 859-63. [PubMed][CrossRef]

20. Lytzen R, Vejlstrup N, Bjerre J et al. Live-born major congenital heart disease in denmark: incidence, detection rate, and termination of pregnancy rate from 1996 to 2013. JAMA Cardiol 2018; 3 : 829-37. [PubMed][CrossRef]

21. Ainsworth S, Wyllie JP, Wren C. Prevalence and clinical significance of cardiac murmurs in neonates. Arch Dis Child Fetal Neonatal Ed 1999; 80: F43-5. [PubMed][CrossRef]

22. Nytt liv og trygg barseltid for familien. Nasjonal faglig retningslinje for barselomsorgen. IS-2057.

Oslo: Helsedirektoratet, 2014.

https://helsedirektoratet.no/retningslinjer/nasjonal-faglig-retningslinje-for-barselomsorgen-nytt-liv-o g-trygg-barseltid-for-familien (15.6.2018).

23. Peterson C, Grosse SD, Oster ME et al. Cost-effectiveness of routine screening for critical congenital heart disease in US newborns. Pediatrics 2013; 132: e595-603. [PubMed][CrossRef]

24. Sands A, Craig B, Mulholland C et al. Echocardiographic screening for congenital heart disease: a randomized study. J Perinat Med 2002;30:307-12. [PubMed][CrossRef]

25. Knowles R, Griebsch I, Dezateux C et al. Newborn screening for congenital heart defects: a systematic review and cost-effectiveness analysis. Health Technol Assess 2005; 9: 1-152, iii-iv. [PubMed][CrossRef]

Publisert: 21. januar 2019. Tidsskr Nor Legeforen. DOI: 10.4045/tidsskr.18.o6o6

Mottatt 4.8.2018, første revisjon innsendt 11.10.2018, godkjent 20.11.2018.

(C) Tidsskrift for Den norske legeforening 2020. Lastet ned fra tidsskriftet.no 